\title{
Prevalence of the elevated urea and creatinine level among hypertensives: Perspective to raise the awareness about disease complications
}

\section{Manal A. Fadl ${ }^{1}$, Huda A. Fadlalmula ${ }^{2}$ and Hisham AbdAllah Hussien $^{3}$}

\author{
${ }^{1}$ Al Neelain University. Faculty of Science and Technology. Department of \\ Biochemistry and Molecular Biology. Khartoum. Sudan. Email: \\ manalfadl1@hotmail.com. \\ ${ }^{2}$ Tropical Medicine Research Institute. National Centre for Research. Department \\ of Epidemiology. Sudan. \\ ${ }^{3}$ Industrial Research and Consultancy Center.
}

\begin{abstract}
An increasing prevalence of hypertension and mortality rate from hypertension complications especially the end stage kidney disease; urge the establishment of routine test for early detection of kidney disease. The aim of this study is to assess the blood urea and creatinine levels in routine visit of hypertensive individuals. Two hundred hypertension patients were enrolled in this study, the demographic and lifestyle data were collected by pre-designed questionnaire. Urea and creatinine were measured for 151 and 159 patient, respectively, using spectrophotometry kits method. Of the studied hypertensive patients, about two third are females (64.5\%), $92 \%$ aged more than 40 years. $32.5 \%$ had diabetes, and $5.5 \%$ had kidney disease. No significant gender difference with regard to the development of complications such as diabetes, stroke, kidney disease and hyperlipidemia ( $\mathrm{P}=0.7-1.0)$. In less than ten years duration of hypertension; $32 \%, 11 \%, 5 \%$ and $49 \%$ of the patients develop diabetes, stroke, kidney disease and hyperlipidemia, respectively, which suggest an inadequate disease control. Of the behavioral risk factors salt; intake is significantly higher in males than in females $(\mathrm{P}=0.022) .38 .4 \%$ and $35.2 \%$ of the analyzed samples had an elevated urea and creatinine level, respectively. Twenty four of samples $(=15 \%)$ had both abnormal urea and creatinine. Within less than five years duration of hypertension; $25 \%$ and $23 \%$ of the patients had abnormal urea and creatinine level, respectively. Insignificant association of neither the abnormal level of urea nor the creatinine with hypertension complications was reported ( $P \geq 0.09$ ), however $36 \%$ and $35 \%$ of the hypertensive who were not previously diagnosed with kidney disease had an abnormal/ elevated urea/creatinine level, respectively. More than thirty five percent of the hypertensives had urea or creatinine measurements above normal levels. Such abnormal level was reported in less than five years duration of

Received

September 14, 2020

Accepted

November 30, 2020

Released

April 30, 2021

Full Text Article

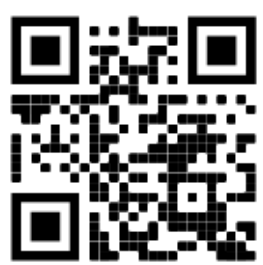

ORCID

(D) 0000-0001-9633-1805 Manal A. Fadl

(1) 0000-0002-6534-167X Huda A. Fadlalmula

(D) 0000-0001-9183-8025 Hisham AbdAllah Hussien
\end{abstract}


hypertension and were also observed in 36\% and 35\% of the hypertensive who were not previously diagnosed with kidney disease, which indicates an uncontrolled hypertension, lack of awareness of disease complications, thereby reflects the importance of the routine measurement of urea and creatinine.

Keywords: Hypertension; Urea; Creatinine; Hypertension complications.

\section{Introduction}

Hypertension is a global health issue with an increased magnitude from an estimated 975 million patients worldwide in 2000 to 1.39 billion in 2010 (Kearney et al., 2005; Mills et al., 2016). In Africa; the overall prevalence of hypertension was $55 \%$ in older people (Kazeet al., 2017), while studies in Sub-Saharan Africa meta-analysis showed different prevalence in different age groups (Ataklte et al., 2015). Another study highlighted a wide range of prevalence of the disease (15.1\%-51.1\%) in 6 cities of subSaharan Africa (Gómez-Olivé et al., 2017).

In Sudan 9.9\% of total population were registered as hypertensive cases at the Ministry of health in 2012, of which 15.9\% live in rural areas (Balla et al., 2014). This percentage was increased in the subsequent years with increasing community based surveys, that showed that the prevalence of hypertension in the urban and rural community of the same State was $35.7 \%$ and $38.2 \%$, respectively (Bushara et al., 2015, 2017), and it was 50\% in one ethnic group also in the same State (Noor et al., 2016).

This increasing prevalence worldwide, in Africa and in Sudan clearly increased the morbidity rate, early age death and affect the productivity as well as economic growth. The estimated death caused by hypertension is half a million in Sub-Saharan Africa (Mensah et al., 2015). 10.4 million death and 218 million disability-adjusted life-years worldwide (GBD 2017 Risk Factor Collaborators, 2018).

The most obvious complications of hypertension are cardiovascular diseases, retinopathy and chronic kidney diseases (Biswas, 2003). WHO (2009) addressed that hypertension is the leading risk factor of cardiovascular diseases. With higher relative risk of death in low and middle income countries (Allen et al., 2017), In Sudan cardiovascular diseases accounts for $11.6 \%$ of deaths taking the higher percent of non-communicable disease death (WHO, 2015). Hypertension with diabetes are the main cause of chronic kidney disease in all high-income and low-income countries (Webster et al., 2017). In Sudan hypertension is the leading cause of end stage renal failure (Elsharif and Elsharif , 2011; Banaga et al., 2015. These complications are preventable by using strategies for prevention and control of hypertension (Patel et al., 2016).

Blood urea concentration test is a biochemical test indicates pre-renal kidney diseases, as urea produced mainly by the liver and excreted by the kidney. It is used as prognostic marker for surviving among myocardial infraction patients and acute coronary syndrome (Luria et al., 1976; Kirtane et al., 2005).

Moreover creatinine test is used specifically for the diagnosis of kidney disease associated with low excretion function of kidneys, hence creatinine is a byproduct of muscle catabolism and excreted by kidneys with limited or no reabsorption. Sudan hypertension guidelines recommend investigation of serum creatinine annually or in case of appearance of signs of target organ damage for good management of hypertension and its complications (Ministry of Health, 2012).

Study conducted in African with a symptomatic high blood pressure revealed a diminished renal function in $16.2 \%$ of the studied group and recommend routine serum 
creatinine measurement for African patients with a symptomatic high blood pressure (Nishijima et al., 2010). It is necessary to rationale the need for routine testing to evaluate kidney function among Sudanese hypertension patients. The aim of this study was to assess blood urea and creatinine levels in hypertensive patients in their routine visit.

\section{Method}

\section{Study design}

A cross-sectional Hospital based study conducted in Khartoum State.

\section{Inclusion criteria}

All hypertensive patients during the study time attending cardiology outpatient clinics of Alrebat Teaching Hospital who agreed to participate were included.

\section{Exclusion criteria}

Pregnant women were excluded.

\section{Demographic data}

A total of 200 hypertensive patients were enrolled in this study. Demographic and risk factor data were obtained by filling pre-designed questionnaire.

\section{Blood samples}

$3 \mathrm{~mL}$ of venous blood sample from hypertensives were collected in EDTA container, blood was centrifuged and plasma was aspirated into another container.

\section{Urea and creatinine measurement}

Using plasma part, urea and creatinine were measured using bio-system kits. After reading the absorption of samples and standard by UV-visible spectrophotometry, the calculation of concentration of samples were made according to instruction sheet provided by bio-system Company. Urea concentration was successfully measured in 151 cases, while creatinine concentration was successfully measured in 159 cases.

\section{Ethical clearance}

Ethical approval was obtained from the Ethical committee at the Faculty of Medical laboratory Science.

\section{Informed consent}

Informed consent was obtained from all participants after explaining the purpose of the study.

\section{Statistical analysis}

The demographic data, the urea and creatinine cross tabulated against demographic data, and comorbidities; all were analyzed using chi square test for SPSS version 21 . P-value $<0.05$ was taken as significant.

\section{Result} 1).

Most of the participants (92\%) are over 40 years old. 64.5\% were females (Figure 


\section{Sex and age distribution}

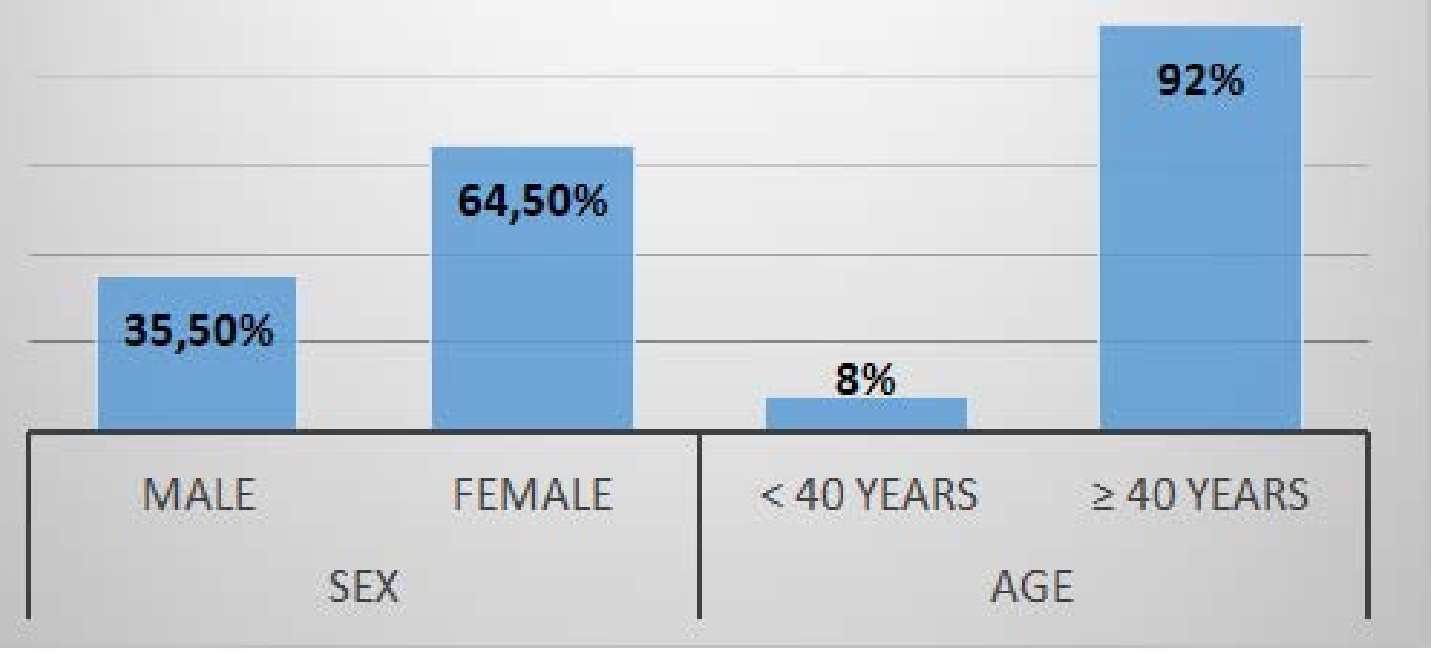

Figure 1. Shows the frequencies (\%) of sex and age groups in the studied hypertensives.

The distribution of comorbidities (diabetes, stroke, kidney disease, and hyperlipidemia) was not differ significantly among different age groups $(\mathrm{p}=0.497,0.863$, 0.699 and 0.537 , respectively) (Table 1), however, such complications were observed with 53\%-64\% frequencies among hypertensive aged 40-60 years old (Table 1), and were also reported among hypertensive in less than ten years duration of hypertension; $32 \%, 11 \%$, $5 \%$ and $49 \%$, respectively (Figure 2 ).

Table 1. Shows the distribution of hypertension comorbidities in different age groups.

\begin{tabular}{|c|c|c|c|c|c|c|c|c|}
\hline \multirow[t]{2}{*}{ Age groups } & \multicolumn{2}{|c|}{ Diabetes Miletus } & \multicolumn{2}{|c|}{ Stroke } & \multicolumn{2}{|c|}{ Kidney disease } & \multicolumn{2}{|c|}{ Hyperlipidemia } \\
\hline & yes & no & yes & no & yes & no & yes & no \\
\hline $20-40$ & $\begin{array}{c}2 \\
3.1 \%\end{array}$ & $\begin{array}{c}14 \\
10.3 \%\end{array}$ & $\begin{array}{c}0 \\
0 \%\end{array}$ & $\begin{array}{c}16 \\
9 \%\end{array}$ & $\begin{array}{c}0 \\
0 \%\end{array}$ & $\begin{array}{c}16 \\
8.5 \%\end{array}$ & $\begin{array}{c}4 \\
4.5 \%\end{array}$ & $\begin{array}{c}12 \\
10.6 \%\end{array}$ \\
\hline $40-60$ & $\begin{array}{c}36 \\
55.4 \% \\
\end{array}$ & $\begin{array}{c}73 \\
54.1 \%\end{array}$ & $\begin{array}{c}12 \\
57.2 \%\end{array}$ & $\begin{array}{c}97 \\
54.2 \%\end{array}$ & $\begin{array}{c}7 \\
63.7 \%\end{array}$ & $\begin{array}{l}102 \\
54 \%\end{array}$ & $\begin{array}{c}46 \\
52.9 \%\end{array}$ & $\begin{array}{c}63 \\
55.8 \%\end{array}$ \\
\hline$>60$ & $\begin{array}{c}27 \\
41.5 \% \\
\end{array}$ & $\begin{array}{c}48 \\
35.6 \% \\
\end{array}$ & $\begin{array}{c}9 \\
42.9 \% \\
\end{array}$ & $\begin{array}{c}66 \\
36.9 \% \\
\end{array}$ & $\begin{array}{c}4 \\
36.4 \% \\
\end{array}$ & $\begin{array}{c}71 \\
37.6 \% \\
\end{array}$ & $\begin{array}{c}37 \\
42.5 \% \\
\end{array}$ & $\begin{array}{c}38 \\
33.8 \% \\
\end{array}$ \\
\hline P value & \multicolumn{2}{|c|}{0.497} & \multicolumn{2}{|c|}{0.863} & \multicolumn{2}{|c|}{0.699} & \multicolumn{2}{|c|}{0.537} \\
\hline
\end{tabular}




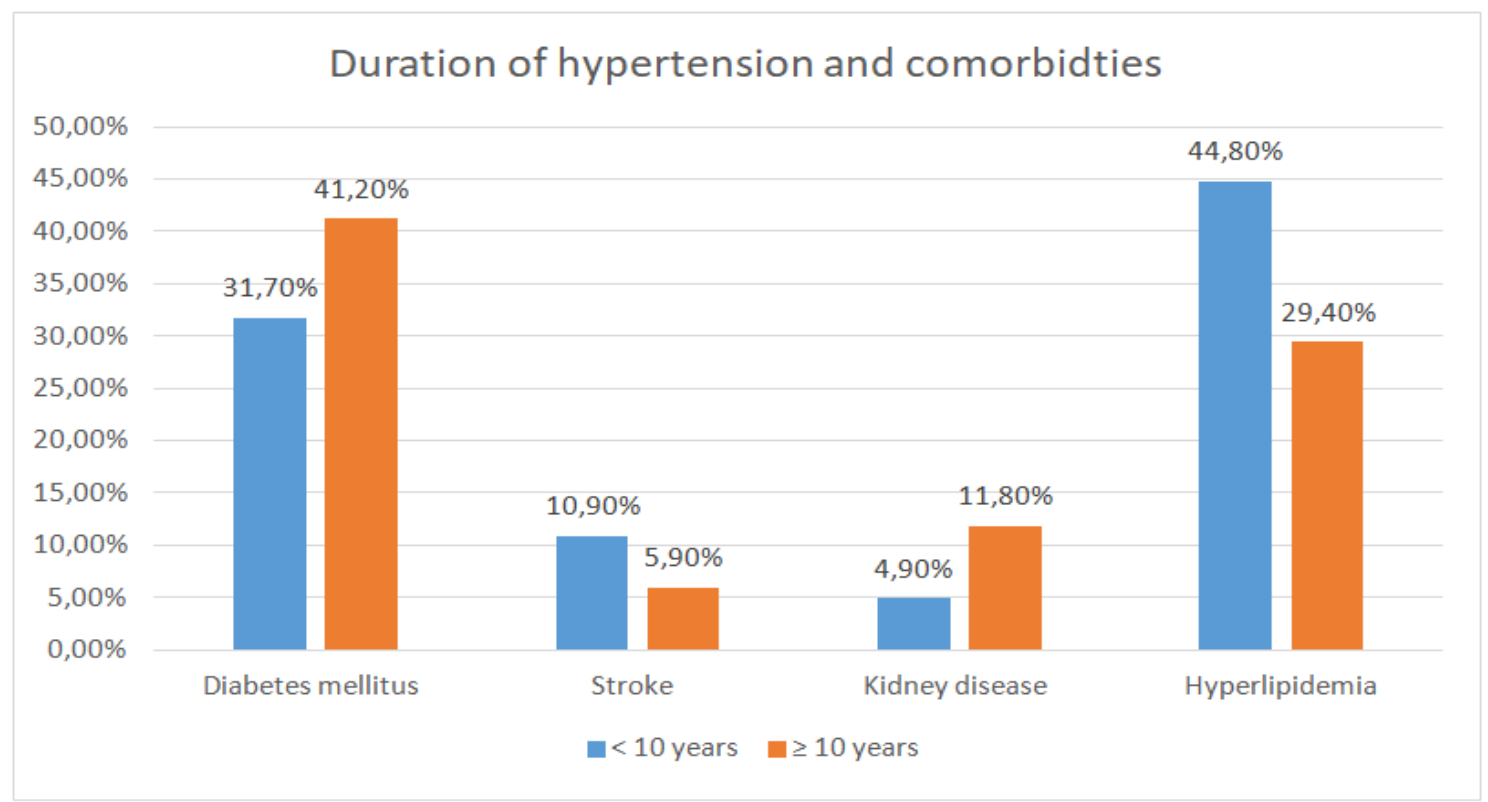

Figure 2. Shows the relation of hypertension complications with disease complications.

No significant gender difference with regard to the development of complications such as diabetes, stroke, and kidney disease and hyperlipidemia $(\mathrm{P}>0.7)$ (Table 2).

Table 2. The distribution of comorbidities among hypertensive males and females.

\begin{tabular}{|c|c|c|c|c|c|}
\hline & \multicolumn{4}{|c|}{ Sex } & \multirow{3}{*}{$P$ value } \\
\hline & \multicolumn{2}{|c|}{ Female $=129$} & \multicolumn{2}{|c|}{ Male $=71$} & \\
\hline & Yes & No & Yes & No & \\
\hline Diabetes mellitus & $41(31.8 \%)$ & $88(68.2 \%)$ & $24(33.8 \%)$ & $47(66.2 \%)$ & 0.87 \\
\hline Stroke & $13(10.1 \%)$ & $116(89.9 \%)$ & $8(11.3 \%)$ & $63(88.7 \%)$ & 0.81 \\
\hline Kidney disease & $8(6.2 \%)$ & $121(93.8 \%)$ & $3(4.2 \%)$ & $68(95.8 \%)$ & 0.75 \\
\hline Hyperlipidemia & $56(43.4 \%)$ & $73(56.6 \%)$ & $31(43.7 \%)$ & $40(56.3 \%)$ & 1.0 \\
\hline
\end{tabular}

Active smoking was not common 6/200 (3\%)among cases both males and female. Sedentary life was not significantly differ in both sexes $(p=0.920)$. Salt intake showed a significant gender difference $(\mathrm{p}=0.022)$. Sixty three percent of males take high to average salt, while $98 \%$ of the females take low to average salt (Table 3).

Table 2. Behavioral risk factors among hypertensive males and females.

\begin{tabular}{|c|c|c|c|c|}
\hline & \multicolumn{2}{|c|}{ Sex } & \multirow{2}{*}{$P$ value } \\
\hline & & Female $=129$ & Male $=71$ & \\
\hline \multirow{2}{*}{ Smoking } & Yes & $1(0.8 \%)$ & $5(7 \%)$ & \multirow{2}{*}{0.02} \\
\hline & No & $128(99.2 \%)$ & $66(93.0 \%)$ & \\
\hline \multirow{2}{*}{ Sedentary life } & Yes & $70(54.3 \%)$ & $38(53.5 \%)$ & \multirow{2}{*}{0.92} \\
\hline & No & $59(45.7 \%)$ & $33(46.5 \%)$ & \\
\hline \multirow{3}{*}{ Salt intake } & High & $2(1.6 \%)$ & $6(8.5 \%)$ & \multirow{3}{*}{0.022} \\
\hline & Average & $90(69.8 \%)$ & $39(54.9 \%)$ & \\
\hline & Low & $37(28.6 \%)$ & $26(36.6 \%)$ & \\
\hline
\end{tabular}


The urea level was successfully measured for 151 patients and the creatinine for 159. $58(38.4 \%)$ and $56(35.2 \%)$ of the hypertensive had an elevated urea and creatinine levels, respectively (Table 4). Abnormal urea and creatinine showed a significant gender difference ( $\mathrm{p} \leq 0.032)$ (Table 4). Within five years duration of hypertension; $25 \%$ and $23 \%$ of the patients had an abnormal urea and creatinine level, respectively (Table 4).

No association between the abnormal level of urea and creatinine and the development of diabetes, stroke, kidney disease or hyperlipidemia ( $p \geq 0.09$ ) (Table 4). However, $36 \%$ and 35\% who were not previously diagnosed with kidney disease had an abnormal urea/creatinine level, respectively (Table 4).

Table 4. Shows the urea and creatinine cross tabulation against sex, hypertension duration and commodities.

\begin{tabular}{|c|c|c|c|c|c|c|c|}
\hline & \multicolumn{2}{|c|}{ Urea (n=151) } & \multirow{2}{*}{$\begin{array}{c}P \\
\text { value }\end{array}$} & \multicolumn{2}{|c|}{ Creatinine (n=159) } & \multirow{2}{*}{$\begin{array}{c}P \\
\text { value }\end{array}$} \\
\hline & & normal & abnormal & & normal & abnormal & \\
\hline \multirow{2}{*}{ Sex } & $\begin{array}{l}\text { Female } \\
(n=129)\end{array}$ & $\begin{array}{c}71 \\
(47.0 \%)\end{array}$ & $\begin{array}{c}33 \\
(21.9 \%)\end{array}$ & \multirow{2}{*}{0.018} & $\begin{array}{c}76 \\
(47.8 \%)\end{array}$ & $\begin{array}{c}32 \\
(20.1 \%)\end{array}$ & \multirow{2}{*}{0.03} \\
\hline & $\begin{array}{l}\text { Male } \\
(\mathrm{n}=71)\end{array}$ & $\begin{array}{c}22 \\
(14.5 \%)\end{array}$ & $\begin{array}{c}25 \\
(16.6 \%)\end{array}$ & & $\begin{array}{c}27 \\
(17.0 \%)\end{array}$ & $\begin{array}{c}24 \\
(15.1 \%)\end{array}$ & \\
\hline \multirow{2}{*}{$\begin{array}{ll}\text { Duration } & \text { of } \\
\text { hypertension }\end{array}$} & $\begin{array}{ll}< & 5 \\
\text { years }\end{array}$ & $\begin{array}{c}62 \\
(41.1 \%)\end{array}$ & $\begin{array}{c}38 \\
(25.2 \%)\end{array}$ & \multirow{2}{*}{1.0} & $\begin{array}{c}69 \\
(43.4 \%)\end{array}$ & $\begin{array}{c}36 \\
(22.6 \%)\end{array}$ & \multirow{2}{*}{0.73} \\
\hline & $\begin{array}{ll}\geq & 5 \\
\text { years } & \\
\end{array}$ & $\begin{array}{c}31 \\
(20.5 \%) \\
\end{array}$ & $\begin{array}{c}20 \\
(13.2 \%) \\
\end{array}$ & & $\begin{array}{c}34 \\
(21.4 \%) \\
\end{array}$ & $\begin{array}{c}20 \\
(12.6 \%) \\
\end{array}$ & \\
\hline \multirow{2}{*}{ Diabetes mellitus } & Yes & $\begin{array}{c}28 \\
(18.5 \%)\end{array}$ & $24(16 \%)$ & \multirow{2}{*}{0.16} & $\begin{array}{c}39 \\
(24.5 \%) \\
\end{array}$ & $15(9.4 \%)$ & \multirow{2}{*}{0.17} \\
\hline & No & $\begin{array}{c}65 \\
(43.0 \%)\end{array}$ & $\begin{array}{c}34 \\
(22.5 \%)\end{array}$ & & $\begin{array}{c}64 \\
(40.3 \%)\end{array}$ & $\begin{array}{c}41 \\
(25.8 \%)\end{array}$ & \\
\hline \multirow{2}{*}{ Stroke } & Yes & $13(8.6 \%)$ & $7(4.6 \%)$ & \multirow{2}{*}{0.81} & $\begin{array}{c}16 \\
(10.1 \%)\end{array}$ & $4(2.5 \%)$ & \multirow{2}{*}{0.14} \\
\hline & No & $\begin{array}{c}80 \\
(53.0 \%)\end{array}$ & $\begin{array}{c}51 \\
(33.8 \%) \\
\end{array}$ & & $\begin{array}{c}87 \\
(54.7 \%)\end{array}$ & $\begin{array}{c}52 \\
(32.7 \%)\end{array}$ & \\
\hline \multirow[b]{2}{*}{ Kidney disease } & Yes & $3(2 \%)$ & $4(2.6 \%)$ & \multirow[b]{2}{*}{0.43} & $7(4.4 \%)$ & $1(0.6 \%)$ & \multirow[b]{2}{*}{0.26} \\
\hline & No & $\begin{array}{c}90 \\
(59.6 \%)\end{array}$ & $\begin{array}{c}54 \\
(35.8 \%)\end{array}$ & & $\begin{array}{c}96 \\
(60.4 \%)\end{array}$ & $\begin{array}{c}55 \\
(34.6 \%)\end{array}$ & \\
\hline \multirow{2}{*}{ Hyperlipidemia } & Yes & $\begin{array}{c}41 \\
(27.2 \%)\end{array}$ & $\begin{array}{c}34 \\
(22.5 \%)\end{array}$ & \multirow{2}{*}{0.09} & $\begin{array}{c}51 \\
(32.1 \%) \\
\end{array}$ & $\begin{array}{c}26 \\
(16.4 \%)\end{array}$ & \multirow{2}{*}{0.74} \\
\hline & No & $\begin{array}{c}52 \\
(34.4 \%)\end{array}$ & $\begin{array}{c}24 \\
(15.9 \%)\end{array}$ & & $\begin{array}{c}52 \\
(32.7 \%)\end{array}$ & $\begin{array}{c}30 \\
(18.8 \%)\end{array}$ & \\
\hline
\end{tabular}

An elevated level of both urea and creatinine were seen in 24 cases (15\%), all of them above forty years old, half were males. Only $25 \%$ of them eating low salt diet, $70.8 \%$ live sedentary life. $29.2 \%, 8.2 \%, 0 \%$ and $58.3 \%$ had diabetes, stroke, kidney disease and hyperlipidemia, respectively.

\section{Discussion}

In Sudan, as in many developing countries; hypertension is considered as one of the public health problems. The increasing burden of hypertension is largely attributable not only to the behavioral factors; unhealthy diet, social stress, lack of regular exercise but also to the lack of awareness and in adequate control of the disease in both urban and rural areas (Sherif et al., 2008; Ataklte et al., 2015). 
Given the fact that, in Sudan hypertension is the leading cause of end stage renal failure (Elsharif and Elsharif, 2011; Banaga et al., 2015); necessitate an increasing need to apply a predictive diagnostic measures, of which is the elevated level of urea and creatinine; an indicator of chronic renal disease, that is strongly related to inadequate treatment of hypertension thereby directly or indirectly lead to renal and cardio or cerebrovascular complications.

This cross-sectional study aimed to measure the urea and creatinine level in hypertensives.

The results showed more than one third of the examined cases had an elevated urea and creatinine concentrations (38.4\% and 35.2\%), respectively, of which 25\% and $23 \%$ of hypertensives had abnormal urea and creatinine, respectively, within less than 5 years of hypertension duration. Which reflects an inadequate treatment or might be due to undiagnosed hypertension for long time (Yahalom et al., 2009). The significant gender relationship between abnormal urea or creatinine, might be due to the high catabolism rate and more male muscle mass compared to the females.

The analysis showed that the abnormal urea and creatinine level were not significantly associated with the reported kidney disease $(p=0.43, p=0.26$, respectively). This result is inconsistent with previous studies that showed that the elevated urea and creatinine levels might be an indicator for hypertensive nephrosclerosis as found by Chang et al. (2012) and also disagreed with study in Sudan which represent hypertension as the leading cause of end stage renal failure (Elsharif and Elsharif, 2011; Banaga et al., 2015). In addition, the elevated level of both urea and creatinine were reported in $15 \%$ of the cases of which $29 \%$ and $8 \%$ developed diabetes and stroke, respectively, which is in agreement with Mohanty et al. (2015). Such situation urges an increased need to deep investigation for the risks and causes of the associated hypertension complications among hypertensive.

The analysis of the demographic data showed that the majority of the studied participants as all were from the outpatient clinics was of female gender, and this is consistent with widely known observation that male gender resistance to engagement in disease management (Muiesan et al., 2016; Sarganas and Neuhauser, 2016; Long et al., 2017), so they are less frequent in outpatient clinics, and found to be more in undiagnosed hypertension in population based studies (Chau et al., 2018; Ahmed et al., 2019).

Moreover, the appearance of complications and comorbidities with 53\%-64\% frequencies among hypertensive aged 40-60 years old which is the reproductive age, and the occurrence of such complications in short disease duration time (less than 10 ears); all these reflect poor understanding and management of the disease as found by Babiker et al. (2013). In addition, such complications are expected to affect the quality of life of hypertensive and their families.

The analysis showed that 3\% of the hypertensives are smokers, $4 \%$ eating high salt diet and 54\% not practicing exercise this agreed with Scisney-Matlock et al. (2009) and Steca et al. (2015) findings. Without changing lifestyle and behavior, the studied cases are suspected to develop more complications than those reported in this study (diabetes mellitus $32.5 \%$, stroke $10.5 \%$, kidney failure $5.5 \%$, and hyperlipidemia $43.5 \%$ ).

\section{Conclusion}

Hypertension complications (diabetes, stroke, kidney disease and hyperlipidemia) were reported with frequencies more than $53 \%$ in hypertensives aged $40-60$ years. More than one third of the examined patients had an elevated urea and creatinine level which occur in less than five years duration of the disease. Moreover, such an elevated level was observed among patients not previously diagnosed with kidney disease. All these suggests either an ignorance, lack of awareness of disease complications, or improper diagnosis or insufficient disease controls or all these together. Such situation definitely adversely 
affects the quality of life of hypertensives and poses a huge economic burden to both the patients and the healthcare providers.

With the adoption of westernized life and the socioeconomic stressful life of Sudanese people; hypertension risk factors might reach an epidemic level, expectedly results in an increasing burden of hypertension. This situation argues the implementation of the cost-effective public awareness and prevention, early detection programs and more reliable and specific biochemical tests should be adopted routinely to decrease the burden of the disease and to prevent disease complications.

\section{Acknowledgments}

The authors thank all the patients who participated in this research. The help of the medical doctor is greatly appreciated.

\section{Conflict of interest}

The authors declare that there is no conflict of interest.

\section{References}

Ahmed, S.; Tariqujjaman, M.; Rahman, M. A.; Hasan, M. Z.; Hasan, M. M. Inequalities in the prevalence of undiagnosed hypertension among Bangladeshi adults: Evidence from a nationwide survey. International Journal for Equity in Health, v. 18, no. 1, Article number 33, 2019. https://doi.org/10.1186/s12939-019-0930-5

Allen, L.; Cobiac, L.; Townsend, N. Quantifying the global distribution of premature mortality from non-communicable diseases. Journal of Public Health, v. 39, no. 4, p. 698703, 2017. https://doi.org/10.1093/pubmed/fdx008

Ataklte, F.; Erqou, S.; Kaptoge, S.; Taye, B.; Echouffo-Tcheugui, J. B.; Kengne, A. P. Burden of undiagnosed hypertension in Sub-Saharan Africa: A systematic review and meta-analysis.
Hypertension,
v. 65,
no. 2 ,
p. 291-298,
2015.

https://doi.org/10.1161/hypertensionaha.114.04394

Babiker, F. A.; Elkhalifa, L. A.; Moukhyer, M. E. Awareness of hypertension and factors associated with uncontrolled hypertension in Sudanese adults. Cardiovascular Journal of Africa, v. 24, no. 6, p. 208-212, 2013. https://doi.org/10.5830/cvja-2013-035

Balla, S. A.; Abdalla, A. A.; Elmukashfi, T. A.; Ahmed, H. A. Hypertension among rural population in four states: Sudan 2012. Global Journal of Health Science, v. 6, no. 3, p. 206-212, 2014. https://doi.org/10.5539/gjhs.v6n3p206

Banaga, A. S.; Mohammed, E. B.; Siddig, R. M.; Salama, D. E.; Elbashir, S. B.; Khojali, M. O.; Babiker, R. A.; Elmusharaf, K.; Homeida, M. M. Causes of end stage renal failure among haemodialysis patients in Khartoum State/Sudan. BMC Research Notes, v. 8, 502, 2015. https://doi.org/10.1186/s13104-015-1509-x

Biswas, S.; Dastidar, D. G.; Roy, K. S.; Pal, S. K.; Biswas, T. K.; Ganguly, S. B. Complications of hypertension as encountered by primary care physician. Journal of the Indian Medical Association, v. 101, no. 4, p. 257-259, 2003.

Bushara, S. O.; Noor, S. K.; Elmadhoun, W. M.; Sulaiman, A. A.; Ahmed, M. H. Undiagnosed hypertension in a rural community in Sudan and association with some features of the metabolic syndrome: How serious is the situation? Renal Failure, v. 37, no. 6, p. 1022-1026, 2015. https://doi.org/10.3109/0886022x.2015.1052951 
Bushara, S. 0.; Noor, S. K.; Ibraheem, A. A.; Elmadhoun, W. M.; Ahmed, M. H. Prevalence of and risk factors for hypertension among urban communities of North Sudan: Detecting a silent killer. Journal of Family Medicine and Primary Care, v. 5, no. 3, p. 605-610, 2016. https://doi.org/10.4103/2249-4863.197317

Chang, Y. K.; Lee, S. J.; Chung, B. H.; Kim, Y. O.; Shin, Y. S. Renal histology in patients with elevated serum creatinine and concurrent normal urinalysis. Clinical Nephrology, v. 77, no. 4, p. 283-289, 2012. https://doi.org/10.5414/cn106999

Chau, K.; Girerd, N.; Zannad, F.; Rossignol, P.; Boivin, J. M. Health-related determinants of undiagnosed arterial hypertension: A population-based study. Family Practice, v. 36, no. 3, p. 276-283, 2018. https://doi.org/10.1093/fampra/cmy075

Elsharif, M. E.; Elsharif, E. G. Causes of end-stage renal disease in Sudan: A single-center experience. Saudi Journal of Kidney Diseases and Transplantation, v. 22, no. 2, p. 373-376, 2011.

GBD 2017 Risk Factor Collaborators. Global, regional, and national comparative risk assessment of 84 behavioural, environmental and occupational, and metabolic risks or clusters of risks for 195 countries and territories, 1990-2017: A systematic analysis for the Global Burden of Disease Study 2017. Lancet, v. 392, no. 10159, p. 1923-1994, 2018. https://doi.org/10.1016/s0140-6736(18)32225-6

Gómez-Olivé, F. X.; Ali, S. A.; Made, F.; Kyobutungi, C.; Nonterah, E.; Micklesfield, L.; Alberts, M.; Boua, R.; Hazelhurst, S.; Debpuur, C.; Mashinya, F.; Dikotope, S.; Sorgho, H.; Cook, I.; Muthuri, S.; Soo, C.; Mukomana, F.; Agongo, G.; Wandabwa, C.; Afolabi, S.; Oduro, A.; Tinto, H.; Wagner, R. G.; Haregu, T.; Wade, A.; Kahn, K.; Norris, S. A.; Crowther, N. J.; Tollman, S.; Sankoh, O.; Ramsay, M. Regional and sex differences in the prevalence and awareness of hypertension: An H3Africa AWI-gen study across 6 sites in Sub-Saharan Africa. Global Heart, v. 12, no. 2, p. 81-90, 2017. https://doi.org/10.1016/j.gheart.2017.01.007

Kaze, A. D.; Schutte, A. E.; Erqou, S.; Kengne, A. P.; Echouffo-Tcheugui, J. B. Prevalence of hypertension in older people in Africa: A systematic review and meta-analysis. Journal of $\begin{array}{llll}\text { Hypertension, } & \text { v. } 35, & \text { no. } 7, & \text { p. } 1345-1352,\end{array}$ https://doi.org/10.1097/hjh.0000000000001345

Kearney, P. M.; Whelton, M.; Reynolds, K.; Muntner, P.; Whelton, P. K.; He, J. Global burden of hypertension: Analysis of worldwide data. Lancet, v. 365, no. 9455, p. 217-223, 2005. https://doi.org/10.1016/s0140-6736(05)17741-1

Kirtane, A. J.; Leder, D. M.; Waikar, S. S.; Chertow, G. M.; Ray, K. K.; Pinto, D. S.; Karmpaliotis, D.; Burger, A. J.; Murphy, S. A.; Cannon, C. P.; Braunwald, E.; Gibson, C. M. Serum blood urea nitrogen as an independent marker of subsequent mortality among patients with acute coronary syndromes and normal to mildly reduced glomerular filtration rates. Journal of the American College of Cardiology, v. 45, no. 11, p.1781-1786, 2005. https://doi.org/10.1016/j.jacc.2005.02.068

Long, E.; Ponder, M.; Bernard, S. Knowledge, attitudes, and beliefs related to hypertension and hyperlipidemia self-management among African-American men living in the Southeastern United States. Patient Education and Counseling, v. 100, no. 5, p. 1000-1006, 2017. https://doi.org/10.1016/j.pec.2016.12.011

Luria, M. H.; Knoke, J. D.; Margolis, R. M.; Hendricks, F. H.; Kuplic, J. B. Acute myocardial infarction: Prognosis after recovery. Annals of Internal Medicine, v. 85, no. 5, p. 561-565, 1976. 
Mensah, G. A.; Roth, G. A.; Sampson, U. K.; Moran, A. E.; Feigin, V. L.; Forouzanfar, M. H.; Naghavi, M.; Murray, C. J. Mortality from cardiovascular diseases in Sub-Saharan Africa, 1990-2013: A systematic analysis of data from the Global Burden of Disease Study 2013. Cardiovascular Journal of Africa, v. 26, no. 2, Suppl. 1, p.S6-S10, 2015. https://doi.org/10.5830/cvja-2015-036

Mills, K. T.; Bundy, J. D.; Kelly, T. N.; Reed, J. E.; Kearney, P. M.; Reynolds, K.; Chen, J.; He, J. Global disparities of hypertension prevalence and control: A systematic analysis of population-based studies from 90 countries. Circulation, v. 134, no. 6, p. 441-450, 2016. https://doi.org/10.1161/circulationaha.115.018912

Ministry of Health. Sudan Hypertension Guideline. Non-Communicable Diseases Directorate Federal. Ministry of Health and Sudan Society of Hypertension (SSH), 2012.

Mohanty, S.; Tripathi, B.; Gupta, B.; Mittal, M. Predictors of early neurological deterioration in patients with acute ischaemic stroke with special reference to blood urea nitrogen (BUN)/creatinine ratio \& urine specific gravity. Indian Journal of Medical Research, v. 141, no. 3, p. 299-307, 2015.

Muiesan, M. L.; Salvetti, M.; Rosei, C. A.; Paini, A. Gender differences in antihypertensive treatment: Myths or legends? High Blood Pressure \& Cardiovascular Prevention, v. 23, no. 2, p. 105-113, 2016. https://doi.org/10.1007/s40292-016-0148-1

Nishijima, D. K.; Paladino, L.; Sinert, R. Routine testing in patients with asymptomatic elevated blood pressure in the ED. The American Journal of Emergency Medicine, v. 28, no. 2, p. 235-242, 2010. https://doi.org/10.1016/j.ajem.2008.11.015

Noor, S. K.; Elsugud, N. A.; Bushara, S. O.; Elmadhoun, W. M.; Ahmed, M. H. High prevalence of hypertension among an ethnic group in Sudan: Implications for prevention. Renal Failure, v. 38, no. 3, p. 352-356, 2016. https://doi.org/10.3109/0886022x.2015.1128839

Patel, P.; Ordunez, P.; DiPette, D.; Escobar, M. C.; Hassell, T.; Wyss, F.; Hennis, A.; Asma, S.; Angell, S. Improved blood pressure control to reduce cardiovascular disease morbidity and mortality: The Standardized Hypertension Treatment and Prevention Project. Journal of Clinical Hypertension, $\quad$ v. 18, no. 12, $\quad$ p. 1284-1294, 2016. https://doi.org/10.1111/jch.12861

Sarganas, G.; Neuhauser, H. K. The persisting gender gap in hypertension management and control in Germany: 1998 and 2008-2011. Hypertens Research, v. 39, no. 6, p. 457-466, 2016. https://doi.org/10.1038/hr.2016.5

Scisney-Matlock, M.; Bosworth, H. B.; Giger, J. N.; Strickland, O. L.; Harrison, R. V.; Coverson, D.; Shah, N. R.; Dennison, C. R.; Dunbar-Jacob, J. M.; Jones, L.; Ogedegbe, G.; Batts-Turner, M. L.; Jamerson, K. A. Strategies for implementing and sustaining therapeutic lifestyle changes as part of hypertension management in African Americans. Postgraduate Medicine, v. 121, no. 3, p. 147-159, 2009. https://doi.org/10.3810/pgm.2009.05.2015

Sherif, S.; Elbaghir, M.; Mamoun, A.; Homeida, M. Prevalence of hypertension in an urban community in Sudan. Khartoum Medical Journal, v. 1, no. 2, p. 72-74, 2008.

Steca, P.; Pancani, L.; Greco, A.; D’Addario, M.; Magrin, M. E.; Miglioretti, M.; Sarini, M.; Scrignaro, M.; Vecchio, L.; Cesana, F.; Giannattasio, C.; Fattirolli, F.; Zanettini, R. Changes in dietary behavior among coronary and hypertensive patients: A longitudinal investigation using the Health Action Process Approach. Applied Psychology Health and Well-Being, v. 7, no. 3, p. 316-339, 2015. https://doi.org/10.1111/aphw.12050

Webster, A. C.; Nagler, E. V.; Morton, R. L.; Masson, P. Chronic kidney disease. Lancet, v. 389, no. 10075, p. 1238-1252, 2017. https://doi.org/10.1016/s0140-6736(16)32064-5 
WHO - World Health Organization. Global health risks: Mortality and burden of disease attributable to selected major risks. Geneva: World Health Organization, 2009.

WHO - World Health Organization. Sudan health profile. Geneva: World Health Organization, Regional Office for the Eastern Mediterranean, 2015.

Yahalom, G.; Schwartz, R.; Schwammenthal, Y.; Merzeliak, O.; Toashi, M.; Orion, D.; Sela, B.; Tanne, D. Chronic kidney disease and clinical outcome in patients with acute stroke. Stroke, v. 40, p. 1296-1303, 2009. https://doi.org/10.1161/strokeaha.108.520882 